\title{
Adipokines in young survivors of childhood acute lymphocytic leukemia revisited: beyond fat mass
}

\begin{abstract}
Adriana Aparecida SivieroMiachon, MD, PhD ${ }^{1,2}$, Angela Maria Spinola-Castro, MD, $\mathrm{PhD}^{1,2}$, Solange Andreoni, $\mathrm{PhD}^{3}$, Maria Lucia de Martino Lee, $\mathrm{MD}^{4}$, Antonio R. Calixto, $\mathrm{MSC}^{5}$, Bruno Geloneze, $M D, P h D^{5}$, Gil Guerra-Junior, $\mathrm{MD}, \mathrm{PhD}^{6}$
\end{abstract}

'Division of Pediatric Endocrinology, Federal University of Sao Paulo UNIFESP/EPM, Sao Paulo, Brazil

${ }^{2}$ Pediatric Oncology Institute - IOP/ GRAACC, Sao Paulo, Brazil

${ }^{3}$ Division of Biostatistics, Department of Preventive Medicine, UNIFESP/EPM, Sao Paulo, Brazil

${ }^{4}$ Division of Pediatric Oncology Hospital Santa Marcelina/TUCCA, Sao Paulo, Brazil

${ }^{5}$ Laboratory of Investigation on Metabolism and Diabetes - LIMED, Faculty of Medical Sciences, State University of Campinas - UNICAMP, Campinas, Brazil

${ }^{6}$ Division of Pediatric Endocrinology, Faculty of Medical Sciences, UNICAMP, Campinas, Brazil

Received: 4 November, 2019

Revised: 1 February, 2020

Accepted: 27 February, 2020

Address for correspondence: Angela Maria Spinola-Castro, MD, $\mathrm{PhD}$

Division of Pediatric Endocrinology, Federal University of Sao Paulo UNIFESP/EPM, 760 Borges Lagoa Street, Sao Paulo 04038-001, Brazil Tel \& Fax: +55-11-5579-9409

E-mail: endocrino@angelaspinola. com.br

https://orcid.org/0000-0003-19740925
Purpose: This cross-sectional study evaluated the relationship between adipokines (leptin, adiponectin, visfatin, and resistin) and adiposity indexes regarding sex and cranial radiotherapy exposure among young acute lymphocytic leukemia survivors. Methods: A multivariate analysis of covariance (MANCOVA) was used to evaluate the joint effect of sex, cranial radiotherapy, and body mass index (BMI) $z$-score (model 1) or fat mass index (FMI) (model 2) on adipokines.

Results: This study included 55 survivors of childhood acute lymphocytic leukemia between 15 and 23 years of age from both sexes (56.4\% female); $43.6 \%$ of the sample had undergone cranial radiotherapy (18-24 Gy). The BMI $z$-score, the $\mathrm{FMI}$, and sex $(P<0.050$ for all) influenced at least one adipokine, while cranial radiotherapy exposure was marginal in model 2 . Parameter estimates from the MANCOVA's final model showed that the BMI $z$-score $(\beta=-0.437, P=0.010)$ and the FMI $(\beta=-0.209, P=0.004)$ negatively influenced adiponectin, while the FMI positively affected resistin ( $\beta=0.142, P=0.020$ ). The relationship between leptin, visfatin, and the adiposity ndexes could not be established. In model 1, females presented with increased adiponectin $(\beta=-1.014, P=0.011)$ and resistin $(\beta=-1.067, P=0.002)$ levels; in model 2 , female sex positively affected adiponectin $(\beta=-1.515, P=0.001)$ and marginally influenced resistin $(\beta=-0.707, P=0.054)$ levels. Cranial radiotherapy negatively determined visfatin levels in both final models $(P<0.050)$.

Conclusion: Changes in body fat may be associated with adipose tissue dysfunction and should be carefully evaluated in survivors of acute lymphocytic leukemia, considering both sex and cranial radiotherapy exposure, to treat disorders that may possibly aggravate their risk for early cardiovascular disease.

Keywords: Precursor cell lymphoblastic leukemia-lymphoma, Radiotherapy, Complications, Body weight, Adipokines, Adipose tissue

\section{Introduction}

Acute lymphocytic leukemia (ALL) is the most common type of cancer diagnosed in childhood. ${ }^{1)}$ As an increasing number of cancer survivors reach adulthood, treatmentrelated sequelae may potentially emerge; adiposity and metabolic syndrome (MS) have been the most extensively studied in ALL patients thus far. ${ }^{2-12)}$ As recommended by the American Cardiology Association, in collaboration with the Council for Cardiovascular Disease in the Young, patients treated for childhood ALL are classified as Tier III, which suggests the clinical presence of criteria for MS, in addition to the epidemiological risk for cardiovascular disease (CVD) early in adulthood. ${ }^{3,4)}$

The traditional role of adipose tissue for energy storage has been reshaped. Adipokines were originally known as the biological markers for MS, and they exert several effects on the central nervous system (CNS), the immune system, and peripheral metabolism; more recently, adipokines are being implicated in additional mechanisms in various diseases, 
such as tumor cell proliferation. ${ }^{13)}$ Adiponectin and serum leptin levels obtained at the time of the ALL diagnosis are considered prognostic markers and are used in ALL risk stratification. Initially, leptin was designated as a stimulatory factor on the proliferation of ALL cells. ${ }^{13-15)}$ Later, leptin was used as an important adiposity index that linked ALL with sex, cranial radiation therapy (CRT) exposure, and features of MS, particularly abdominal adiposity and insulin resistance (IR). Increased leptin and low adiponectin concentrations are possibly involved with an altered fat distribution and metabolic abnormalities among ALL survivors. ${ }^{12,16-24)}$

To date, previous data comprising this ALL cohort have confirmed the relationship between CRT exposure and an altered fat distribution. ${ }^{6)}$ Male sex also plays a role in determining leptin concentrations, but no effect of CRT has been identified, ${ }^{16,22)}$ which is contrary to the well-established reports so far. ${ }^{17-20,23,24)}$ Thus, the aim of this study was to further evaluate this relationship between leptin and other adipokines (adiponectin, visfatin, and resistin) with body fat, sex, and CRT exposure in survivors of childhood ALL.

\section{Materials and methods}

\section{Study population}

This investigation was one component of a cross-sectional study of a randomly selected sample of ALL survivors from the Pediatric Oncology Institute (Federal University of Sao Paulo, Brazil) who were admitted for treatment between May 1991 and June 2003.

ALL participants were treated with a previously described international protocol, the Brazilian Cooperative Group for Treatment of Childhood Acute Lymphocytic Leukemia (GBTLI). CRT was administered to those at high risk for relapse and/or to those with CNS involvement (> 5\% blast cells in the cerebrospinal fluid). ${ }^{25,26)}$

The inclusion and exclusion criteria have been published elsewhere ${ }^{6}$ and included an age between 15 and 24 years, complete clinical remission, no therapy for at least the past 2 years, complete pubertal development according to Tanner stage, ${ }^{27,28)}$ final adult height, and a normal hormonal profile (either spontaneously or under hormonal replacement therapy). Exclusion criteria were as follows: anorexigens, insulinsensitivity medications, growth hormone administration, bone marrow transplantation, pregnancy, postpartum status, and Down syndrome.

The ALL survivors were divided into 2 groups based upon their exposure to CRT. Medical records and clinical examinations were used to evaluate the characteristics of patients and their diseases and respective treatments, such as sex, age at diagnosis, age at assessment, past medical history, medications, dose of CRT (when employed), and time posttherapy.

\section{Measurements}

All the measurements were previously described in studies that used the same ALL cohort. ${ }^{6,21,29)}$

1) Adiposity indexes

Body composition variables comprised the body mass index (BMI) and fat mass index (FMI). BMI was calculated and analysed as a $z$-score, according to the National Center for Health Statistics (2000) Centers for Disease Control and Prevention Growth Charts. ${ }^{30)}$ Body fat mass was assessed using dual energy $\mathrm{x}$-ray absorptiometry (DXA) obtained using a Hologic Discovery 4500 (QDR-4500A; Hologic Inc., Bedford, MA, USA) scanner. The fat distribution indexes included methods to assess visceral adipose tissue (VAT) and subcutaneous adipose tissue (SAT); both were measured according to the methods described elsewhere. ${ }^{6,21,29)}$

\section{2) Adipokines}

The leptin (in $\mathrm{ng} / \mathrm{mL}$ ), adiponectin (in $\mu \mathrm{g} / \mathrm{mL}$ ), visfatin, and resistin (both in $\mathrm{ng} / \mathrm{mL}$ ) assays and their respective intra-assay and interassay coefficients of variation, minimum detection limit, and specificities have been published elsewhere. ${ }^{21,29)}$

\section{Statistical analysis}

The mean and standard deviation values were used to summarize the numerical variables, while the frequency count and percentages described the categorical variables of the sampled participants' characteristics. A t-test for independent samples was used to compare numerical variables, and a Fisher exact test for categorical comparisons was also carried out according to the exposure to CRT.

A multivariate analysis of covariance (MANCOVA) was performed with adipokines (leptin, adiponectin, visfatin, and resistin) as the dependent variables and sex, CRT exposure, and BMI $z$-score (model 1) or sex, CRT exposure, and FMI (model 2) as the covariates. The BMI z-score was chosen to represent adiposity indexes in the MANCOVA analysis in order to compare the results with previous data comprising part of this ALL cohort. Leptin levels did not display a normal distribution according to the Kolmogorov-Sminorv test, so they were transformed into their natural logarithm (ln_Leptin). For all tests, $P<0.050$ was considered statistically significant. All statistical analysis were performed using IBM SPSS Statistics ver. 20.0 (IBM Co., Armonk, NY, USA).

\section{Results}

\section{Participant characteristics}

The selected sample consisted of 55 patients: 31 females (56.4\%) and 24 males (43.6\%). There was no difference in the 
exposure to CRT among the sexes $(P=0.426)$. The mean age at the time of the study assessment was $18.6 \pm 2.5$ years, with a range from 15.0-22.9 years. Patients had been a mean of $7.5 \pm 3.9$ years of age at the time of their ALL diagnosis, and they were currently an average of $8.5 \pm 3.4$ years posttreatment. The ALL patients who had undergone CRT were older compared to the nonirradiated group $(19.5 \pm 2.1$ years vs. $17.9 \pm 2.5$ years, $P=0.018)$.

The ALL participants completed the GBTLI international protocol; 24 ALL survivors (43.6\%) received CRT treatment at a dosage of either 18 or $24 \mathrm{~Gy}$. Three patients also underwent alternative protocols to the GBTLI without complementary CRT due to relapses. Among the irradiated survivors, 1 patient also received spinal irradiation, and 2 patients received testicular radiation therapy (24 Gy).

In regards to the adiposity indexes, the ALL patients who had undergone irradiation presented with an increased FMI $(7.7 \pm 3.3$ $\mathrm{kg} / \mathrm{m}^{2}$ vs. $\left.5.8 \pm 2.8 \mathrm{~kg} / \mathrm{m}^{2}, P=0.025\right)$ and VAT $\left(138.0 \pm 68.7 \mathrm{~cm}^{3}\right.$ vs. $\left.88.8 \pm 52.6 \mathrm{~cm}^{3}, P=0.004\right)$ compared to the nonirradiated group. Visfatin levels were decreased among the group exposed to CRT compared to the nonirradiated ALL patients $(8.8 \pm 1.7 \mathrm{ng} /$ $\mathrm{mL}$ vs. $10.3 \pm 2.9 \mathrm{ng} / \mathrm{mL}, P=0.030$ ). Table 1 displays further data according to the exposure to CRT. These data are preliminary and have not been adjusted for sex, BMI, or FMI.

\section{Multivariate analysis of covariance}

An initial model (not shown) tested the interaction between sex, CRT exposure, chronological age, BMI $z$-score, FMI, and their interactions. As age and interactions were not significant $(P>0.050)$, the final model was composed of sex, CRT exposure, and BMI $z$-score (model 1) or sex, CRT exposure, and FMI (model 2). These final models suggested that sex, BMI $z$-score, or FMI influenced at least one adipokine $(P<0.050$ for all), while CRT did not, and these results were marginal in model 2 $(P=0.075)$ (Table 2).

\section{1) BMI $z$-score (model 1)}

To determine which adipokine was influenced by sex and BMI $z$-score, parameter estimates from the MANCOVA were analysed and revealed that the BMI $z$-score negatively influenced adiponectin $(\beta=-0.437, P=0.010)$, whereas male sex negatively determined both adiponectin $(\beta=-1.014, P=0.011)$ and resistin $(\beta=-1.067, P=0.002)$ levels (Table 3).

\section{2) FMI (model 2)}

To recognize which adipokine was influenced by sex, CRT,

Table 2. MANCOVA testing effect of sex, CRT, and BMI or FMI on adipokines, among ALL survivors

\begin{tabular}{|c|c|c|c|c|}
\hline \multirow{2}{*}{ Variable } & \multicolumn{4}{|c|}{ MANCOVA } \\
\hline & $F$ & $\mathrm{DF}_{\text {num }}$ & $D F_{\text {den }}$ & $P$-value \\
\hline \multicolumn{5}{|l|}{ Model 1} \\
\hline Male sex & 3.82 & 4 & 48 & 0.009 \\
\hline CRT_exposure & 1.74 & 4 & 48 & 0.157 \\
\hline BMl z-score & 2.87 & 4 & 48 & 0.033 \\
\hline \multicolumn{5}{|l|}{ Model 2} \\
\hline Male sex & 3.85 & 4 & 48 & 0.009 \\
\hline CRT_exposure & 2.28 & 4 & 48 & 0.075 \\
\hline FMI $\left(\mathrm{kg} / \mathrm{m}^{2}\right)$ & 4.85 & 4 & 48 & 0.002 \\
\hline
\end{tabular}

MANCOVA, multivariate analysis of covariance; CRT, cranial radiotherapy; BMI, body mass index; FMI, fat mass index; $A L L$, acute lymphocytic leukemia; DFnum, numerator degrees of freedom; $\mathrm{DF}_{\mathrm{den},}$ denominator degrees of freedom.

Model 1, BMl z-score; model 2, FMI.

Reference: female, nonirradiated.

Table 1. Summary of general characteristics, adiposity indexes, and adipokines of ALL survivors, according to CRT exposure

\begin{tabular}{|c|c|c|c|c|}
\hline \multirow{2}{*}{ Variable } & \multirow{2}{*}{ Total $(n=55)$} & \multicolumn{2}{|c|}{ Exposure to CRT } & \multirow{2}{*}{$P$-value } \\
\hline & & No $(n=31)$ & Yes $(n=24)$ & \\
\hline Sex & & & & 0.426 \\
\hline Female & $31(100.0)$ & $19(61.3)$ & $12(50.0)$ & \\
\hline Male & $24(100.0)$ & $12(38.7)$ & $12(50.0)$ & \\
\hline Age at ALL diagnosis (yr) & $7.5 \pm 3.9(2.1-17.0)$ & $7.4 \pm 4.0(2.1-17.0)$ & $7.5 \pm 3.9(2.3-13.8)$ & 0.920 \\
\hline Age at assessment (yr) & $18.6 \pm 2.5(15.0-22.9)$ & $17.9 \pm 2.5(15.0-22.9)$ & $19.5 \pm 2.1(15.0-22.8)$ & $0.018^{*}$ \\
\hline Time posttherapy (yr) & $8.5 \pm 3.4(2.5-16.4)$ & $8.1 \pm 3.5(2.5-14.9)$ & $9.1 \pm 3.5(2.6-16.4)$ & 0.307 \\
\hline BMI (z-score) & $0.07 \pm 1.18(-2.88$ to 2.14$)$ & $-0.08 \pm 1.21(-2.88$ to 2.11$)$ & $0.25 \pm 1.14(-2.44$ to 2.14$)$ & 0.302 \\
\hline $\mathrm{FMI}\left(\mathrm{kg} / \mathrm{m}^{2}\right)$ & $6.6 \pm 3.1(1.8-15.5)$ & $5.8 \pm 2.8(1.8-11.8)$ & $7.7 \pm 3.3(2.5-15.5)$ & $0.025^{*}$ \\
\hline Visceral adipose tissue $\left(\mathrm{cm}^{3}\right)$ & $110.3 \pm 64.5(21.9-265.3)$ & $88.8 \pm 52.6(21.9-217.8)$ & $138.0 \pm 68.7(47.3-265.3)$ & $0.004^{*}$ \\
\hline Subcutaneous adipose tissue $\left(\mathrm{cm}^{3}\right)$ & $357.6 \pm 233.3(36.2-1,077.4)$ & $285.8 \pm 177.6(36.2-681.1)$ & $450.4 \pm 265.9(38.3-1,077.4)$ & 0.008 \\
\hline Leptin (ng/mL) & $10.9 \pm 4.5(8.0-31.5)$ & $11.8 \pm 5.8(8.0-31.5)$ & $9.8 \pm 1.0(8.2-11.7)$ & 0.095 \\
\hline In_Leptin (In_ng/mL) & $2.33 \pm 0.28(2.08-3.45)$ & $2.39 \pm 0.36(2.08-3.45)$ & $2.27 \pm 0.10(2.10-2.46)$ & 0.130 \\
\hline Adiponectin ( $\mu \mathrm{g} / \mathrm{mL})$ & $3.8 \pm 1.5(1.1-7.1)$ & $3.9 \pm 1.5(1.1-7.1)$ & $3.7 \pm 1.6(1.3-7.1)$ & 0.569 \\
\hline Visfatin (ng/mL) & $9.6 \pm 2.6(6.2-19.7)$ & $10.3 \pm 2.9(6.2-19.7)$ & $8.8 \pm 1.7(6.3-13.7)$ & $0.030^{*}$ \\
\hline Resistin (ng/mL) & $7.7 \pm 1.3(5.0-10.3)$ & $7.6 \pm 1.3(4.9-10.0)$ & $7.8 \pm 1.3(5.0-10.3)$ & 0.683 \\
\hline
\end{tabular}

Values are presented as number (\%) or mean \pm standard deviation (range).

ALL, acute lymphocytic leukemia; CRT, cranial radiotherapy; BMI, body mass index; FMI, fat mass index; In: natural logarithm.

${ }^{*} P<0.05$, statistically significant differences. 
Table 3. Parameter estimates from MANCOVA's final model 1 (BMI z-score), according to each adipokine, among ALL survivors

\begin{tabular}{|c|c|c|c|c|c|}
\hline Variable & $\beta$ & Standard error & $95 \% \mathrm{Cl}$ & $t$ & $P$-value \\
\hline \multicolumn{6}{|c|}{ In_Leptin (In_ng/mL) } \\
\hline Intercept & 2.354 & 0.058 & $2.24-2.47$ & 40.25 & $<0.001$ \\
\hline Male sex & 0.087 & 0.077 & -0.07 to 0.24 & 1.13 & 0.265 \\
\hline CRT_exposure & -0.117 & 0.078 & -0.27 to 0.04 & -1.50 & 0.139 \\
\hline BMI z-score & -0.032 & 0.033 & -0.09 to 0.03 & -0.99 & 0.327 \\
\hline \multicolumn{6}{|c|}{ Adiponectin $(\mu \mathrm{g} / \mathrm{mL})$} \\
\hline Intercept & 4.305 & 0.291 & $3.72-4.89$ & 14.78 & $<0.001$ \\
\hline Male sex & -1.014 & 0.383 & -1.78 to -0.24 & -2.65 & 0.011 \\
\hline CRT_exposure & 0.022 & 0.386 & -0.75 to 0.79 & 0.06 & 0.956 \\
\hline BMI z-score & -0.437 & 0.162 & -0.76 to -0.11 & -2.69 & 0.010 \\
\hline \multicolumn{6}{|l|}{ Visfatin (ng/mL) } \\
\hline Intercept & 10.277 & 0.520 & $9.23-11.32$ & 19.78 & $<0.001$ \\
\hline Male sex & 0.052 & 0.683 & -1.32 to 1.42 & 0.08 & 0.939 \\
\hline CRT_exposure & -1.606 & 0.689 & -2.99 to -0.22 & -2.33 & 0.024 \\
\hline BMI z-score & 0.313 & 0.290 & -0.27 to 0.89 & 1.08 & 0.285 \\
\hline \multicolumn{6}{|l|}{ Resistin (ng/mL) } \\
\hline Intercept & 8.068 & 0.252 & $7.56-8.57$ & 31.96 & $<0.001$ \\
\hline Male sex & -1.067 & 0.332 & -1.73 to -0.40 & -3.21 & 0.002 \\
\hline CRT_exposure & 0.205 & 0.335 & -0.47 to 0.88 & 0.61 & 0.544 \\
\hline BMI z-score & 0.190 & 0.141 & -0.09 to 0.47 & 1.35 & 0.183 \\
\hline
\end{tabular}

MANCOVA, multivariate analysis of covariance; BMI, body mass index; ALL, acute lymphocytic leukemia; Cl, confidence interval; CRT, cranial radiotherapy.

Reference: female, nonirradiated.

Table 4. Parameter estimates from MANCOVA's final model 2 (FMI), according to each adipokine, among ALL survivors

\begin{tabular}{|c|c|c|c|c|c|}
\hline Variable & $\beta$ & Standard error & $95 \% \mathrm{Cl}$ & t & $P$-value \\
\hline \multicolumn{6}{|c|}{ In_Leptin (In_ng/mL) } \\
\hline Intercept & 2.364 & 0.115 & $2.13-2.59$ & 20.52 & $<0.001$ \\
\hline Male sex & 0.088 & 0.087 & -0.09 to 0.26 & 1.01 & 0.315 \\
\hline CRT_exposure & -0.125 & 0.084 & -0.29 to 0.04 & -1.49 & 0.142 \\
\hline FMI $\left(\mathrm{kg} / \mathrm{m}^{2}\right)$ & -0.001 & 0.014 & -0.03 to 0.03 & -0.09 & 0.925 \\
\hline \multicolumn{6}{|c|}{ Adiponectin $(\mu \mathrm{g} / \mathrm{mL})$} \\
\hline Intercept & 5.748 & 0.560 & $4.63-6.87$ & 10.26 & $<0.001$ \\
\hline Male sex & -1.515 & 0.423 & -2.36 to -0.67 & -3.58 & 0.001 \\
\hline CRT_exposure & 0.328 & 0.407 & -0.49 to 1.15 & 0.80 & 0.424 \\
\hline FMI $\left(\mathrm{kg} / \mathrm{m}^{2}\right)$ & -0.209 & 0.070 & -0.35 to -0.07 & -2.98 & 0.004 \\
\hline \multicolumn{6}{|l|}{ Visfatin (ng/mL) } \\
\hline Intercept & 9.070 & 1.006 & $7.05-11.09$ & 9.01 & $<0.001$ \\
\hline Male sex & 0.481 & 0.759 & -1.04 to 2.00 & 0.63 & 0.529 \\
\hline CRT_exposure & -1.881 & 0.732 & -3.35 to -0.41 & -2.57 & 0.013 \\
\hline $\mathrm{FMI}\left(\mathrm{kg} / \mathrm{m}^{2}\right)$ & 0.175 & 0.126 & -0.08 to 0.43 & 1.39 & 0.170 \\
\hline \multicolumn{6}{|l|}{ Resistin (ng/mL) } \\
\hline Intercept & 7.085 & 0.475 & $6.13-8.04$ & 14.91 & $<0.001$ \\
\hline Male sex & -0.707 & 0.358 & -1.43 to 0.01 & -1.97 & 0.054 \\
\hline CRT_exposure & -0.043 & 0.345 & -0.74 to 0.65 & -0.12 & 0.902 \\
\hline FMI $\left(\mathrm{kg} / \mathrm{m}^{2}\right)$ & 0.142 & 0.059 & $0.02-0.26$ & 2.40 & 0.020 \\
\hline
\end{tabular}

MANCOVA, multivariate analysis of covariance; FMI, fat mass index; ALL, acute lymphocytic leukemia; Cl, confidence interval; CRT, cranial radiotherapy.

Reference: female, nonirradiated.

and FMI, the final MANCOVA model revealed that FMI negatively determined adiponectin $(\beta=-0.209, P=0.004)$ and positively influenced resistin $(\beta=0.142, P=0.020)$ levels.
Adiponectin was also negatively influenced by male sex $(\beta=-1.515, P=0.001)$, while resistin was negatively but only marginally influenced $(\beta=-0.707, P=0.054)$ (Table 4$)$. 
Even though the influence of CRT exposure was marginal in the previous analysis (model 2, Table 2), its effect on visfatin was evident in both the final model $1(\beta=-1.606, P=0.024)$ and model 2 ( $\beta=-1.881, P=0.013)$; the visfatin levels decreased in the ALL group participants who had been subjected to CRT. Leptin was not influenced by sex, CRT exposure, BMI $z$-score, or FMI thus far $(P>0.050$, all covariates).

The scatterplots for each adipokine by BMI $z$-score according to sex and the presence of CRT are shown in Fig. 1A-D. The scatterplots of each adipokine by FMI according to sex and the presence of CRT are presented in Supplementary Fig. 1A-D.

\section{Discussion}

This study investigated the relationship between adipokines and body fat among young survivors of ALL according to their sex and CRT levels. The main finding was that adiponectin and resistin were both influenced by sex, while CRT exposure influenced only visfatin levels.

Adipokines are secreted by the adipose tissue and are biological markers of MS; these substances exert their actions in a wide variety of pathophysiological processes, including obesity, inflammation, glucose metabolism, and endothelial dysfunction. ${ }^{16-24,29)}$ Based on previous studies performed using this same ALL cohort, both FMI and abdominal adipose tissue are influenced by CRT exposure, while female sex only affects FMI. ${ }^{6}$ There is increasing interest in assessing adiposity and its relationship with adipokines among ALL patients, as adipokine dysfunction due to excessive obesity might influence weight gain and MS traits in this group of patients, even many years after therapy withdrawal. To date, sex and CRT exposure are important determinants of this relationship and represent the most important factors to be analysed in ALL survivors to understand their role in metabolic disease. ${ }^{2-12,16-24,29)}$ Late endocrine effects of cancer and its treatment are considered to create a synergic interaction between the host's genetic characteristics, including sex, the disease itself, and treatment type, including chemotherapy and CRT exposure. ${ }^{4,5)}$

In this study, the relationship between body fat (represented by the BMI $z$-score and FMI) and adipokines could be established only between adiponectin (negatively related) and resistin (positively related), even though all adipokines are secreted by fat. The absence of this relationship between fat mass, visfatin, and particularly leptin may also be explained by other factors that could have negatively influenced or confounded this relationship, such as the number of participants in this cohort (55 ALL survivors) and/or the BMI $z$-score and FMI interval, which were not sufficient to detect such a relationship. ${ }^{16-24,29)}$

In regards to CRT exposure, visfatin was the only affected
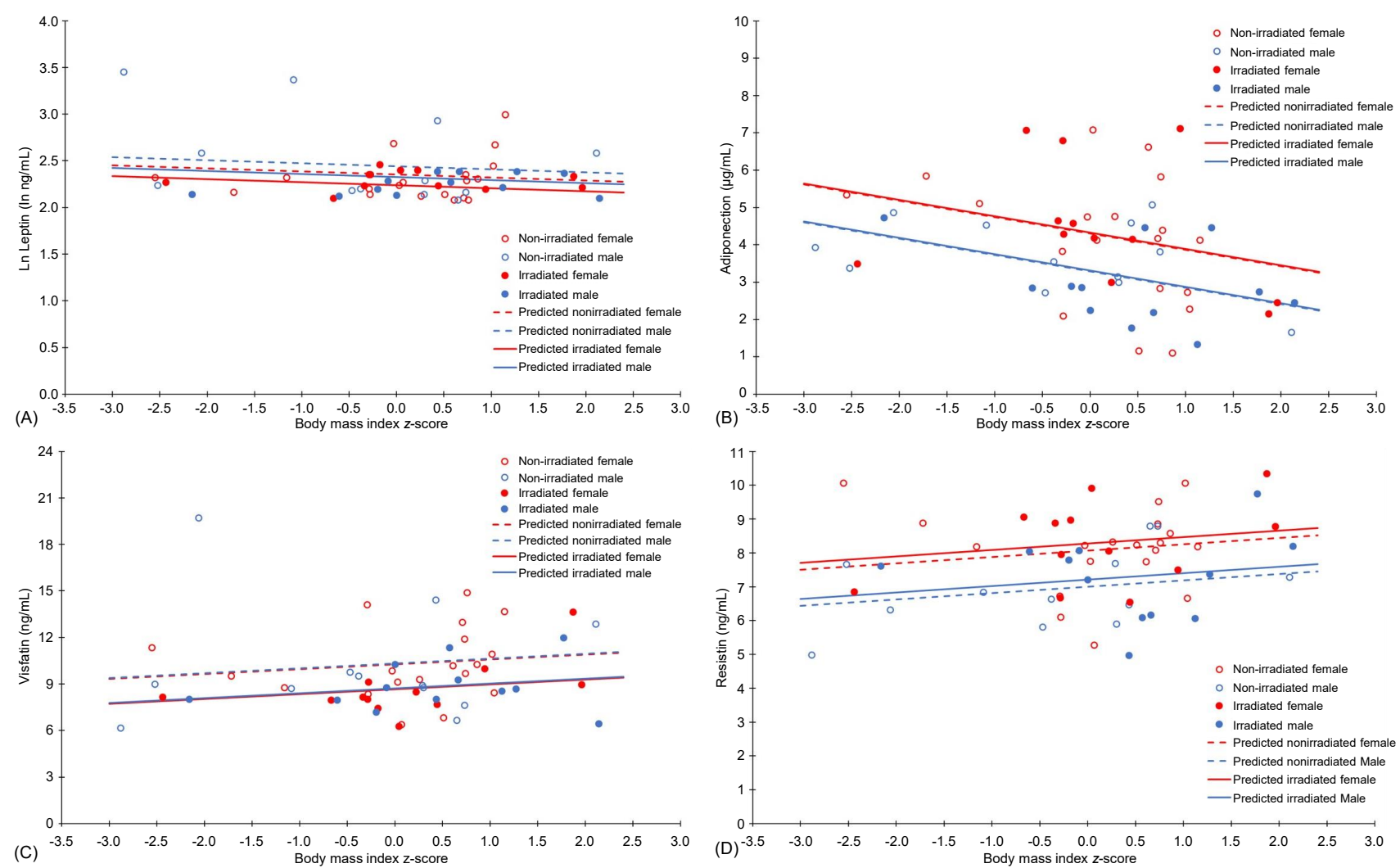

Fig. 1. Scatterplots of adipokines by body mass index z-score according to sex and a history of cranial radiation therapy. (A) In_Leptin, (B) adiponectin, (C) visfatin, (D) resistin. 
adipokine; its levels decreased in the group exposed to CRT; the CRT dosage in this sample varied from 18-24 Gy. These results contrast with previous data that showed higher leptin and decreased adiponectin concentrations among ALL patients who underwent CRT. ${ }^{17,20,23,24)}$ However, the leptin profile among part of the actual ALL cohort has already demonstrated no effect of CRT when the patients were a mean of 3 years away from their last therapy. ${ }^{16)}$ To date, limited data exist on visfatin and resistin levels among ALL survivors, and the role of these adipokines on weight gain and adiposity in this particular population is still poorly understood and needs to be established. ${ }^{17,29)}$

There is a definite sexual dimorphism among various adipokine levels in the general population that is usually influenced by sexual hormones, body fat accumulation, and age. Unfortunately, there is no information among adipokine reference values according to age and sex, and with the available data it is not possible to explain the reason why only adiponectin and resistin were both influenced by female sex thus far. Mice models and further longitudinal evaluations in humans may help us further explain sex differences and the implications of hormones, fat, and age in this process. In male mice, leptin increases with age, whereas adiponectin levels remain constant. In females, both adiponectin and leptin levels increase with age. Plasma resistin declines with age despite an increase in adiposity in both genders. Resistin levels are higher in female than in male mice at all ages, whereas leptin and adiponectin levels are similar; sexual dimorphism is apparent only in older mice, with higher levels recorded in females. ${ }^{31)}$

In ALL patients, leptin is considered a marker of adiposity that is predominantly expressed in SAT and females; other adipokines have not been studied or have been poorly studied among ALL survivors thus far. In this study population, it was not possible to determine any influence of adiposity indexes, sex, or CRT exposure on leptin itself, which disagrees with previously published studies that have associated leptin with

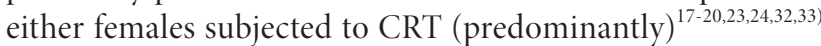
or male sex despite CRT exposure ${ }^{16,22)}$ and in ALL patients at a younger age and with a shorter posttreatment interval. The BMI $z$-score (and FMI) as the representative of adiposity indexes might have shown a positive effect on this adipokine, as observed in a previous study with part of this actual ALL cohort. ${ }^{16)}$ To date, despite the available data, it is still not possible to explain these differences concerning sexual dimorphism on leptin in these survivors of ALL; however, ethnic and/or genetic differences might be speculated.

Adiponectin concentrations were inversely related to BMI $z$-score and FMI and were increased in females; likewise leptin, adiponectin showed no effects from CRT exposure. An effect of CRT on adiponectin levels was expected based on previous studies. ${ }^{17,20)}$ However, it was not established in this study population so far.

To date, visfatin levels have been poorly studied in ALL survivors; no effect of sex, BMI $z$-score, or FMI was identified on this adipokine in this ALL cohort. Visfatin levels decreased among ALL patients subjected to CRT. This adipokine was originally identified as having insulin-mimetic properties and might be considered a clinical marker of vascular damage and systemic inflammation, as it is enhanced in metabolic diseases such as obesity and type 2 diabetes mellitus. ${ }^{34)}$ Their positive properties on bone metabolism have been recently demonstrated among ALL survivors, with visfatin representing a possible link between bone and adipose tissue. ${ }^{29)}$ In addition, several studies have investigated the role of visfatin in intertissular joint communication, which suggests that a local inflammatory effect of this particular adipokine may be present in rheumatoid arthritis, osteoarthritis, and/or other rheumatic diseases. ${ }^{35,36)}$ Recently, decreased visfatin levels were considered to be additional biochemical markers for remission in ALL patients. $^{37)}$

Resistin is an adipokine that potentiates IR and seems to reflect abdominal fat deposition, even though this adipokine has been poorly studied among ALL survivors to date. ${ }^{17,29)}$ In this study, resistin levels were not related to either exposure to CRT or BMI $z$-score among this ALL cohort. Nonetheless, resistin was negatively determined by male sex (in model 1 and marginally in model 2) and positively determined by FMI (model 2).

Adipokines (particularly leptin and adiponectin) are clearly involved in MS physiopathology, although their mechanism of action that links immune function with metabolism is still poorly understood. They are secreted by adipose tissue and are involved in leukocyte migration, tumor growth, tumor invasion, and metastasis, including ALL. Nonetheless, the mechanisms underlying the molecular response need to be further detailed and are vital for understanding the complex association between cancer, obesity, and metabolic dysfunction. ${ }^{38)}$

This study included 55 survivors of ALL from a single institution at a mean of 8.5 years after therapy withdrawal. Other factors may have influenced the variables studied here, such as chronological age and shorter posttreatment interval, compared to other populations, in addition to extreme parental care and continuous medical support. ${ }^{2,7-9,17-20,23,24)}$ Although ALL patients exposed to CRT were assessed at an increased chronologic age, this difference was not considered to be clinically relevant. None of the participants were within the period known as the adiposity rebound, which occurs 2 years after the completion of ALL treatment where there is a predictable increase in adiposity indexes, as previously described in this ALL cohort. ${ }^{6,39)}$ In addition, unfortunately there are no data on adipokines or their relationship with adiposity indexes either at the time of the ALL diagnosis or during ALL therapy.

Overall, the current data suggest that CRT administration did not play a major role in altering adipokine levels in young people treated for ALL; however, female sex positively influenced adiponectin and resistin concentrations. Future studies should further analyse the relationship between adipokines and adiposity indexes with the aim to understand adipocyte dysfunction and further the linking between immune system, cancer, and metabolism, in order to treat disorders that may possibly aggravate ALL survivors' risk for early CVD. 


\section{Ethical statement}

This study was approved by the Ethics Research Committee of the Federal University of Sao Paulo (No. 1197/07) and is in accordance with the 1964 Helsinki Declaration and its later amendments. To participate in this study, patients and/or parents, when appropriate, signed an informed consent form.

\section{Conflict of interest}

No potential conflict of interest relevant to this article was reported.

\section{Acknowledgments}

This work was supported by grants from the Sao Paulo State Research Foundation (no 06/06162-9 to G.G-J.). The authors thank all the patients and their families, Ricardo Silva Ribeiro for performing the computed tomography scans, and Geni da Silva Santos for carrying out the DXA imaging.

\section{Supplementary material}

Supplementary Fig. 1 can be found via https://doi. org/10.6065/apem.1938174.087.

\section{References}

1. Redaelli A, Laskin BL, Stephens JM, Botteman MF, Pashos CL. A systematic literature review of the clinical and epidemiological burden of acute lymphoblastic leukaemia (ALL). Eur J Cancer Care (Engl) 2005;14:53-62.

2. Link K, Moëll C, Garwicz S, Cavallin-Ståhl E, Björk J, Thilén U, et al. Growth hormone deficiency predicts cardiovascular risk in young adults treated for acute lymphoblastic leukemia in childhood. J Clin Endocrinol Metab 2004;89:5003-12.

3. Kavey RE, Allada V, Daniels SR, Hayman LL, McCrindle BW, Newburger JW, et al. Cardiovascular risk reduction in high-risk pediatric patients: a scientific statement from the American Heart Association Expert Panel on Population and Prevention Science; the Councils on Cardiovascular Disease in the Young, Epidemiology and Prevention, Nutrition, Physical Activity and Metabolism, High Blood Pressure Research, Cardiovascular Nursing, and the Kidney in Heart Disease; and the Interdisciplinary Working Group on Quality of Care and Outcomes Research: endorsed by the American Academy of Pediatrics. Circulation 2006;114:2710-38.

4. Siviero-Miachon AA, Spinola-Castro AM, Guerra-Junior G. Detection of metabolic syndrome features among childhood cancer survivors: a target to prevent disease. Vasc
Health Risk Manag 2008;4:825-36.

5. Siviero-Miachon AA, Spinola-Castro AM, Guerra-Junior G. Adiposity in childhood cancer survivors: insights into obesity physiopathology. Arq Bras Endocrinol Metab 2009;53:190-200.

6. Siviero-Miachon AA, Spinola-Castro AM, Lee ML, Andreoni S, Geloneze B, Lederman H, et al. Cranial radiotherapy predisposes to abdominal adiposity in survivors of childhood acute lymphocytic leukemia. Radiat Oncol 2013;8:39.

7. van Waas M, Neggers SJ, Pieters R, van den Heuvel-Eibrink MM. Components of the metabolic syndrome in 500 adult long-term survivors of childhood cancer. Ann Oncol 2010;21:1121-6.

8. Oeffinger KC, Buchanan GR, Eshelman DA, Denke MA, Andrews TC, Germak JA, et al. Cardiovascular risk factors in young adult survivors of childhood acute lymphoblastic leukemia. J Pediatr Hematol Oncol 2001;23:424-30.

9. Janiszewski PM, Oeffinger KC, Church TS, Dunn AL, Eshelman DA, Victor RG, et al. Abdominal obesity, liver fat, and muscle composition in survivors of childhood acute lymphoblastic leukemia. J Clin Endocrinol Metab 2007;92:3816-21.

10. Spinola-Castro AM, Siviero-Miachon AA, Guerra-Junior $\mathrm{G}$, Geloneze B. Insulin resistance in childhood cancer survivors: a link between metabolic syndrome features. In: Yao EB, editor. Insulin resistance: new research. New York: Nova Science Publishers, 2009:235-51.

11. Siviero-Miachon AA, Spinola-Castro AM, Guerra-Junior G. Metabolic syndrome and cancer: cause or consequence? J Metabol Syndro 2012;1:e103.

12. Barbosa-Cortés L, López-Alarcón M, Mejía-Aranguré JM, Klünder-Klünder M, Del Carmen Rodríguez-Zepeda M, Rivera-Márquez $\mathrm{H}$, et al. Adipokines, insulin resistance, and adiposity as a predictors of metabolic syndrome in child survivors of lymphoma and acute lymphoblastic leukemia of a developing country. BMC Cancer 2017;17:125.

13. Aref S, Ibrahim L, Azmy E, Al Ashary R. Impact of serum adiponectin and leptin levels in acute leukemia. Hematology 2013;18:198-203.

14. Hino M, Nakao T, Yamane T, Ohta K, Takubo T, Tatsumi N. Leptin receptor and leukemia. Leuk Lymphoma 2000;36:457-61.

15. Hamed NA, Sharaki OA, Zeidan MM. Leptin in acute leukaemias: relationship to interleukin- 6 and vascular endothelial growth factor. Egypt J Immunol 2003;10:57-66.

16. Siviero-Miachon AA, Spinola-Castro AM, TostaHernandez PD, de Martino Lee ML, Petrilli AS. Leptin assessment in acute lymphocytic leukemia survivors: role of cranial radiotherapy? J Pediatr Hematol Oncol 2007;29:776-82.

17. Moschovi M, Trimis G, Vounatsou M, Katsibardi K, Margeli A, Damianos A, et al. Serial plasma concentrations of adiponectin, leptin, and resistin during therapy in children with acute lymphoblastic leukemia. J Pediatr Hematol 
Oncol 2010;32:e8-13.

18. Kohler JA, Moon RJ, Wright S, Willows E, Davies JH. Increased adiposity and altered adipocyte function in female survivors of childhood acute lymphoblastic leukaemia treated without cranial radiation. Horm Res Paediatr 2011;75:433-40.

19. Bülow B, Link K, Ahrén B, Nilsson AS, Erfurth EM. Survivors of childhood acute lymphoblastic leukaemia, with radiation-induced GH deficiency, exhibit hyperleptinaemia and impaired insulin sensitivity, unaffected by 12 months of GH treatment. Clin Endocrinol (Oxf) 2004;61:683-91.

20. Tonorezos ES, Vega GL, Sklar CA, Chou JF, Moskowitz CS, Mo Q, et al. Adipokines, body fatness, and insulin resistance among survivors of childhood leukemia. Pediatr Blood Cancer 2012;58:31-6.

21. Siviero-Miachon AA, Spinola-Castro AM, de Martino Lee ML, de Castro Monteiro CM, de Camargo Carvalho AC, Calixto AR, et al. Subcutaneous adipose tissue plays a beneficial effect on subclinical atherosclerosis in young survivors of acute lymphocytic leukemia. Vasc Health Risk Manag 2015;11:479-88.

22. Jahnukainen K, Heikkinen R, Henriksson M, Andersson S, Ivaska KK, Puukko-Viertomies LR, et al. Increased body adiposity and serum leptin concentrations in very longterm adult male survivors of childhood acute lymphoblastic leukemia. Horm Res Paediatr 2015;84:108-15.

23. Brennan BM, Rahim A, Blum WF, Adams JA, Eden OB, Shalet SM. Hyperleptinaemia in young adults following cranial irradiation in childhood: growth hormone deficiency or leptin insensitivity? Clin Endocrinol (Oxford) 1999;50:163-9.

24. Karaman S, Ercan O, Yildiz I, Bolayirli M, Celkan T, Apak H, et al. Late effects of childhood ALL treatment on body mass index and serum leptin levels. J Pediatr Endocrinol Metab 2010;23:669-74.

25. Brandalise S, Viana M, Pereira W, Loggetto S, Zouain G, Lee $\mathrm{M}$, et al. Chemotherapy in 853 unselected childhood ALL patients. Results of the Brazilian multicenter trial GBTLI ALL-93 [abstract]. Pediatr Blood Cancer 2004;43:s399.

26. Scrideli CA, Assumpção JG, Ganazza MA, Araújo M, Toledo SR, Lee ML, et al. A simplified minimal residual disease polymerase chain reaction method at early treatment points can stratify children with acute lymphoblastic leukemia into good and poor outcome groups. Haematologica 2009;94:781-9.
27. Marshall WA, Tanner JM. Variations in pattern of pubertal changes in girls. Arch Dis Child 1969;44:291-303.

28. Marshall WA, Tanner JM. Variations in the pattern of pubertal changes in boys. Arch Dis Child 1970;45:13-23.

29. Siviero-Miachon AA, Spinola-Castro AM, de Martino Lee ML, Calixto AR, Geloneze B, Lazaretti-Castro M, et al. Visfatin is a positive predictor of bone mineral density in young survivors of acute lymphocytic leukemia. J Bone Miner Metab 2017;35:73-82.

30. National Center for Health Statistics (2000). Clinical growth charts [Internet]. Centers for Disease Control and Prevention; [2019 Aug 1]. Available from: http://www.cdc. gov/growthcharts/clinical_charts.htm.

31. Gui Y, Silha JV, Murphy LJ. Sexual dimorphism and regulation of resistin, adiponectin, and leptin expression in the mouse. Obes Res 2004;12:1481-91.

32. Blum WF, Englaro P, Hanitsch S, Juul A, Hertel NT, Müller J, et al. Plasma leptin levels in healthy children and adolescents: dependence on body mass index, body fat mass, gender, pubertal stage, and testosterone. J Clin Endocrinol Metab 1997;82:2904-10.

33. Brandão CM, Lombardi MT, Nishida SK, Hauache OM, Vieira JG. Serum leptin concentration during puberty in healthy nonobese adolescents. Braz J Med Biol Res 2003;36:1293-6.

34. Romacho T, Sánchez-Ferrer CF, Peiró C. Visfatin/Nampt: an adipokine with cardiovascular impact. Mediators Inflamm 2013;2013:946427.

35. Dozio E, Corsi MM, Ruscica M, Passafaro L, Steffani L, Banfi G, et al. Adipokine actions on cartilage homeostasis. Adv Clin Chem 2011;55:61-79.

36. Scotece M, Conde J, Gómez R, López V, Lago F, GómezReino JJ, et al. Beyond fat mass: exploring the role of adipokines in rheumatic diseases. ScientificWorldJournal 2011;11:1932-47.

37. Skoczen S, Tomasik PJ, Gozdzik J, Fijorek K, KrasowskaKwiecien A, Wiecha O, et al. Visfatin concentrations in children with leukemia before and after stem cell transplantation. Exp Hematol 2014;42:252-60.

38. Lang K, Ratke J. Leptin and adiponectin: new players in the field of tumor cell and leukocyte migration. Cell Commun Signal 2009;7:27.

39. Reilly JJ, Kelly A, Ness P, Dorosty AR, Wallace WH, Gibson BE, et al. Premature adiposity rebound in children treated for acute lymphoblastic leukemia. J Clin Endocrinol Metab 2001;86:2775-8. 